\title{
Application of Bi-State Magnetic Material to Automotive Offset-Coupled IPM Starter/Alternator Machine
}

\author{
Ayman M. EL-Refaie, Student Member, IEEE, Russell Manzke, and Thomas M. Jahns, Fellow, IEEE
}

\begin{abstract}
This paper investigates a new approach to designing high-speed interior permanent-magnet (IPM) synchronous machines using a bi-state soft magnetic material. The bi-state material can have its normally high magnetic permeability permanently reduced in localized regions to that of air by means of heat treatment. This new work significantly expands a previous investigation by considering offset-coupled IPM machines that make it possible to significantly increase the rotor speed while retaining all of the other specifications of the 6-kW starter/alternator application. Lumped-parameter models, Monte Carlo optimization, and both electromagnetic and structural finite-element analysis are used to develop new offset-coupled IPM machine designs with the new material at speeds of $40000 \mathrm{r} / \mathrm{min}$ or higher. Results from this work demonstrate that the bi-state material offers a promising approach for designing high-speed IPM machines that offer weight and volume advantages compared to their lower speed counterparts at comparable system cost.
\end{abstract}

Index Terms-Magnetic materials, permanent-magnet (PM) machines, rotating machine mechanical factors, synchronous machines.

\section{INTRODUCTION}

$\mathbf{T}$ HE design of high-speed permanent synchronous magnets poses a combination of demanding electromagnetic and mechanical design challenges. For surface-magnet machines, a variety of special rotor construction techniques have been developed to mechanically retain the fragile magnets, including stainless steel annular shells and special high-strength tapes [1], [2].

Interior permanent-magnet (IPM) synchronous machines offer an inherent advantage over surface-magnet machines for high-speed applications since the magnets are buried inside the soft magnetic rotor laminations that naturally provide mechanical retention. Fig. 1 shows a cross section of one pole of a well-known "multi-barrier" IPM machine [3] that uses conventional radial laminations with one or more layers of

Paper IPCSD 04-014, presented at the 2003 Industry Applications Society Annual Meeting, Salt Lake City, UT, October 12-16, and approved for publication in the IEEE TRANSACTIONS ON INDUSTRY APPLICATIONS by the Electric Machines Committee of the IEEE Industry Applications Society. Manuscript submitted for review June 13, 2003 and released for publication February 18, 2004. This work was supported by the MIT/Industry Consortium on Advanced Automotive Electrical/Electronic Components and Systems.

A. M. EL-Refaie and T. M. Jahns are with the Department of Electrical and Computer Engineering, University of Wisconsin, Madison, WI 53706 USA (e-mail: elrefaie@cae.wisc.edu; jahns@engr.wisc.edu).

R. Manzke is with the Wisconsin Center For Space Automation and Robotics, University of Wisconsin, Madison, WI 53706 USA (e-mail: rcmanzke@wisc.edu).

Digital Object Identifier 10.1109/TIA.2004.827470

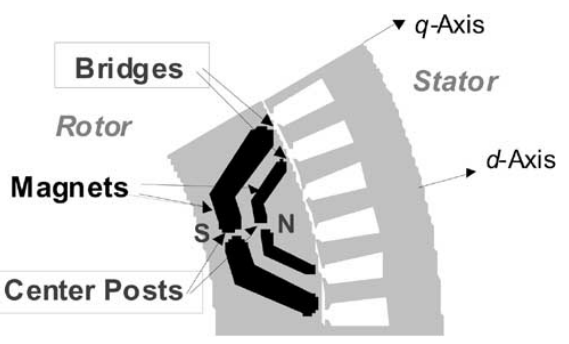

Fig. 1. One pole of a multi-barrier IPM machine design with a unitary rotor lamination showing bridges and center posts.

internal cavities to contain the magnets. As indicated in Fig. 1, the rotor laminations are unitary with narrow bridges and/or center posts to hold the outer pole pieces in place.

IPM machines present their own distinct set of design challenges for high-speed operation. Considering the Fig. 1 rotor lamination design, the bridges and center posts must be designed to be sufficiently narrow so that they thoroughly saturate without shunting too much of the magnet flux. On the other hand, these same linking structures must be sufficiently wide to provide structural integrity at high rotational speeds. Developing the optimum tradeoff between these electromagnetic and mechanical constraints is a major design issue requiring careful attention [4].

Recently, a new bi-state soft magnetic material has become available [5] that offers some intriguing possibilities for decoupling the magnetic and electromagnetic design issues. While one state of this material has a high magnetic permeability, heat treatment of the material at temperatures above $1100{ }^{\circ} \mathrm{C}$ causes the material to transform to a low-permeability state $\left(\mu_{r} \approx 1\right)$ that it retains after it is cooled below that threshold temperature. This opens the possibility of heat treating the bi-state material in localized areas to "unmagnetize" those regions, creating effective air gaps while retaining the basic mechanical integrity of the original sample.

The technical viability of this approach has already been demonstrated in some prototype electrical machines and actuators [6]-[8]. The bi-state material magnetic material is an attractive candidate for application in IPM machines since it provides an avenue for substantially widening the bridges and center posts for improved mechanical strength without suffering the penalty of excessive magnet flux loss through these structures. Previous work [9] has demonstrated that the material can be successfully applied to design an IPM machine for an automotive direct-drive starter/alternator (S/A) application with substantially higher mechanical integrity than 
TABLE I

COMPARISON OF Key PROPERTIES OF THE YEP-FA1 BI-STATE SOFT Magnetic Material AND M19 Silicon STEEL

\begin{tabular}{c|c|c|c}
\hline & M19 & \multicolumn{2}{|c}{ YEP-FA1 } \\
\hline Composite & Si-Fe & \multicolumn{2}{|c}{ Fe-17.5Cr-0.5C } \\
\hline Magnetic Process & - & \multicolumn{2}{|c}{ Heat Treatment } \\
\hline Magnetic Properties & Magnetic & Magnetic & Nonmag \\
\hline Permeability & 8000 & 900 & $\leq 1.01$ \\
\hline Coercive Force[KA/m] & 0.038 & 0.5 & - \\
\hline Saturation Flux Density [T] & 1.9 & 1.3 & - \\
\hline \multicolumn{4}{|c|}{ Mechanical Properties } \\
\hline Yield Stress [MPa] & $320-350$ & 640 & 350 \\
\hline UTS [MPa] & 503 & 770 & 930 \\
\hline Elongation [\%] & 23 & 15 & 40 \\
\hline Hardness [Hv] & 151 & 220 & 220 \\
\hline
\end{tabular}

a comparable machine using conventional silicon steel (M19) for the rotor laminations.

Application of this bi-state material in electromechanical apparatus entails its own set of engineering tradeoffs. Table I provides a summary of the key magnetic and mechanical properties of this bi-state magnetic material (designated YEP-FA1 by its manufacturer) in the two right-most columns [10]. Corresponding properties for conventional M19-grade steel are provided in the same table for convenient comparisons.

Inspection of the properties for the two states of the YEP-FA1 material shows that heat treatment reduces the permeability by $900: 1$. As a result of this heat treatment, the mechanical yield stress suffers to a much lesser degree, dropping by a factor of less than two from 640 to $350 \mathrm{MPa}$. Even in its heat-treated condition, Table I shows that the material's yield stress is as high as that of M19 steel (350 MPa).

Additional tradeoffs are also apparent in Table I. In exchange for the bi-state magnetic characteristics, the new material offers lower saturated flux density and higher coercive force values than conventional silicon steels. Furthermore, the cost of this new material in the stainless steel family is expected to be higher than silicon steel.

The previous work [9] with a 6-kW direct-drive starter/alternator application showed that significant improvements in structural integrity can be achieved using this new bi-state material for the rotor lamination. However, this work also showed that machine and drive cost suffer because the direct-drive speed constraint makes it impossible to take full advantage of the new material's properties.

This paper presents designs of offset-coupled IPM machines using the bi-state magnetic material that meet the same $6-\mathrm{kW}$ starter/alternator requirements except that the machine speed is allowed to increase above the crankshaft speed using either a belt or gears. This new work shows that the advantages of the material are utilized far more effectively to increase the IPM machine power density and reduce its cost when the rotor speed constraint is removed.

The direct-drive automotive starter-alternator (S/A) application that has previously been addressed using conventional M19-grade silicon steel [11] was selected in order to provide a convenient basis for direct comparisons. An identical set

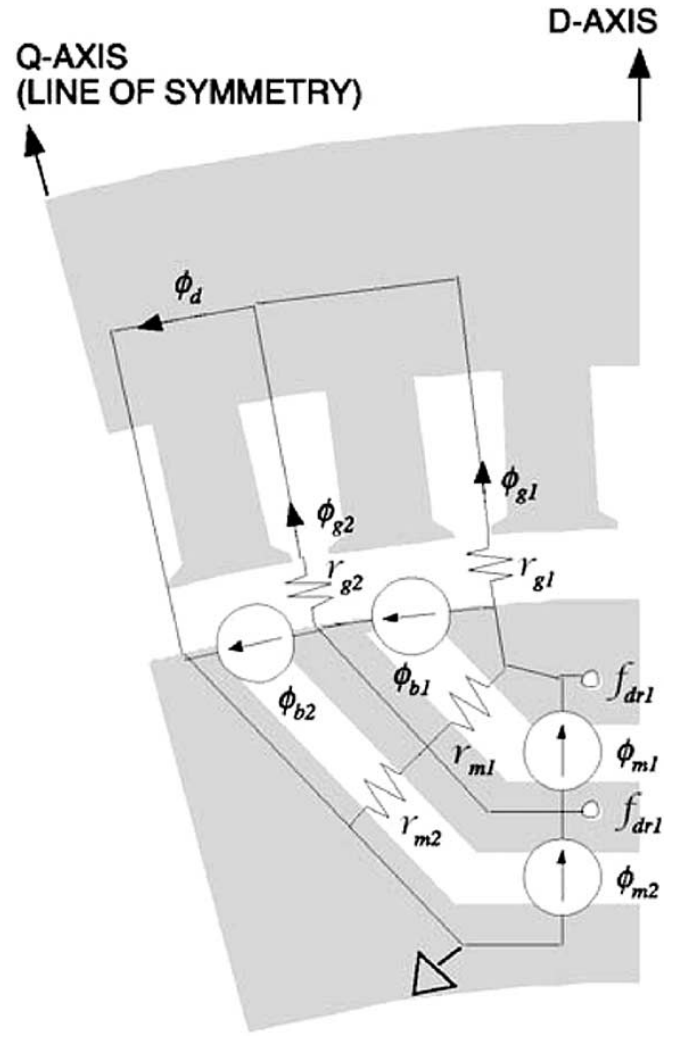

Fig. 2. Magnetic equivalent circuit for calculating magnet flux linkage $\lambda_{\mathrm{PM}}$.

of performance specifications was used for this new design exercise, including $150 \mathrm{~N} \cdot \mathrm{m}$ starting torque and $6-\mathrm{kW}$ power generation at $6000 \mathrm{r} / \mathrm{min}$. The actual machine rotor speed and torque requirements are scaled appropriately based on the selected speed ratio.

Performance comparisons are provided using a variety of criteria including volume, size, weight, cost, and peak rotor mechanical stress. Although specific to this machine, such comparisons are useful for providing guidance on how this material can be applied most effectively to other applications.

\section{MACHINE DESIGN APPROACH}

The design tool used for this investigation is the same one used previously to design the starter/alternator machine using conventional silicon steel for both the stator and rotor [11]. More specifically, this design software combines a nonlinear lumped-parameter magnetic circuit model of the IPM machine with a Monte Carlo optimization algorithm in order to find the best machine design to minimize cost. The magnetic lumped-parameter model developed to analyze the IPM machine includes magnetic saturation that particularly affects the rotor iron permeances along the $q$ axis, orthogonal to the magnet field orientation. [12].

Electromagnetic finite-element analysis (FEA) is used for the final machine designs in order to verify key electrical parameters and to evaluate their torque-ripple characteristics. A lumped-parameter thermal model is also incorporated into the software to evaluate all of the key steady-state temperatures within each candidate machine design [13]. 
TABLE II

Comparison of Machine Parameters for Baseline Direct-Drive S/A Machine AND the Four Offset-Coupled DesignS

\begin{tabular}{|c|c|c|c|c|c|}
\hline & $\begin{array}{l}\text { Baseline Direct- } \\
\text { Drive S/A (M19 } \\
\text { Stator \& Rotor) } \\
\text { 1:1 Speed Ratio }\end{array}$ & $\begin{array}{c}\text { Design \#1: } \\
\text { Non-Mgnetic Center } \\
\text { Posts } \\
\text { 3:1 Speed Ratio }\end{array}$ & $\begin{array}{c}\text { Design \#2: } \\
\text { Non-Magnetic } \\
\text { Center Posts } \\
\text { 4:1 Speed Ratio }\end{array}$ & $\begin{array}{l}\text { Design \#3: } \\
\text { Non-Magnetic } \\
\text { Center Posts } \\
\text { 5:1 Speed Ratio }\end{array}$ & $\begin{array}{l}\text { Design \#4: } \\
\text { Non-Magnetic } \\
\text { Center Posts } \\
6: 1 \text { Speed Ratio }\end{array}$ \\
\hline Number of Poles & 12 & 6 & 6 & 4 & 4 \\
\hline Max. Rotor Gen. Speed & $6,000[\mathrm{r} / \mathrm{min}]$ & $18,000[\mathrm{r} / \mathrm{min}]$ & $24,000[\mathrm{r} / \mathrm{min}]$ & $30,000[\mathrm{r} / \mathrm{min}]$ & $36,000[\mathrm{r} / \mathrm{min}]$ \\
\hline Max Rotor Overspeed & $10,000[\mathrm{r} / \mathrm{min}]$ & $30,000[\mathrm{r} / \mathrm{min}]$ & $40,000[\mathrm{r} / \mathrm{min}]$ & $50,000[\mathrm{r} / \mathrm{min}]$ & $60.000[\mathrm{r} / \mathrm{min}]$ \\
\hline Stator Material & M19 & M19 & M19 & M19 & M19 \\
\hline Rotor Material & M19 & YEP-FA1 & YEP-FA1 & YEP-FA1 & YEP-FA1 \\
\hline $\begin{array}{l}\text { Magnet Remanent Flux } \\
\text { Dens. }\end{array}$ & $0.28[\mathrm{~T}]$ & $0.235[\mathrm{~T}]$ & $0.295[\mathrm{~T}]$ & $0.39[\mathrm{~T}]$ & $0.39[\mathrm{~T}]$ \\
\hline Bridge Thickness & $1[\mathrm{~mm}]$ & $1[\mathrm{~mm}]$ & $1[\mathrm{~mm}]$ & $1[\mathrm{~mm}]$ & $1[\mathrm{~mm}]$ \\
\hline Center Post Thickness & $1[\mathrm{~mm}]$ & $5[\mathrm{~mm}]$ & $8[\mathrm{~mm}]$ & $12[\mathrm{~mm}]$ & $12[\mathrm{~mm}]$ \\
\hline Stator Outer Diameter & $271.7[\mathrm{~mm}]$ & $180.2[\mathrm{~mm}]$ & $173.3[\mathrm{~mm}]$ & $171.8[\mathrm{~mm}]$ & $169.3[\mathrm{~mm}]$ \\
\hline Active Length & $60[\mathrm{~mm}]$ & $72.3[\mathrm{~mm}]$ & $62.1[\mathrm{~mm}]$ & 69. $[\mathrm{mm}]$ & $70.2[\mathrm{~mm}]$ \\
\hline Total Length & $90[\mathrm{~mm}]$ & $107.7[\mathrm{~mm}]$ & $94.39[\mathrm{~mm}]$ & $115.6[\mathrm{~mm}]$ & $115[\mathrm{~mm}]$ \\
\hline Rotor Outer Radius & $108.4[\mathrm{~mm}]$ & $54.5[\mathrm{~mm}]$ & $48.9[\mathrm{~mm}]$ & $43.8[\mathrm{~mm}]$ & $41.9[\mathrm{~mm}]$ \\
\hline Rotor Inner Radius & $83.1[\mathrm{~mm}]$ & $28.3[\mathrm{~mm}]$ & $25.6[\mathrm{~mm}]$ & $22.7[\mathrm{~mm}]$ & $22.1[\mathrm{~mm}]$ \\
\hline Air Gap Length & $0.635[\mathrm{~mm}]$ & $0.635[\mathrm{~mm}]$ & $0.635[\mathrm{~mm}]$ & $0.635[\mathrm{~mm}]$ & $0.635[\mathrm{~mm}]$ \\
\hline $\begin{array}{l}\text { Effective Air Gap } \\
\text { Thickness }\end{array}$ & $0.696[\mathrm{~mm}]$ & $0.677[\mathrm{~mm}]$ & $0.699[\mathrm{~mm}]$ & $0.711[\mathrm{~mm}]$ & $0.71[\mathrm{~mm}]$ \\
\hline Air Gap Radius & $109[\mathrm{~mm}]$ & $55.1[\mathrm{~mm}]$ & $49.5[\mathrm{~mm}]$ & $44.4[\mathrm{~mm}]$ & $42.5[\mathrm{~mm}]$ \\
\hline Active Rotor Volume & $2215\left[\mathrm{~cm}^{3}\right]$ & $674\left[\mathrm{~cm}^{3}\right]$ & $466.3\left[\mathrm{~cm}^{3}\right]$ & $418.3\left[\mathrm{~cm}^{3}\right]$ & $386.5\left[\mathrm{~cm}^{3}\right]$ \\
\hline Winding Factor & 0.9224 & 0.9224 & 0.9224 & 0.9224 & 0.9224 \\
\hline Number of Series Turns & 24 & 12 & 12 & 8 & 8 \\
\hline Number of Slots & 72 & 36 & 36 & 24 & 24 \\
\hline $\begin{array}{c}\text { Thickness of inner } \\
\text { magnet }\end{array}$ & $2.9[\mathrm{~mm}]$ & $2.3[\mathrm{~mm}]$ & $2.1[\mathrm{~mm}]$ & $1.9[\mathrm{~mm}]$ & $1.8[\mathrm{~mm}]$ \\
\hline $\begin{array}{c}\text { Thickness of outer } \\
\text { magnet }\end{array}$ & $5.7[\mathrm{~mm}]$ & $4.4[\mathrm{~mm}]$ & $4.3[\mathrm{~mm}]$ & $3.8[\mathrm{~mm}]$ & $3.7[\mathrm{~mm}]$ \\
\hline Span of inner magnet & 86.28 [elect. degrees] & 91.5 [elect. degrees] & 101.9[elect. degrees] & 98.38 [elect. degrees] & 97.71[elect. degrees] \\
\hline Span of outer magnet & 140.8 [elect. degrees] & 140.8 [elect. degrees] & 162 [elect. degrees] & 142.1 elect. degrees] & 142.7 [elect. degrees] \\
\hline
\end{tabular}

The new bi-state magnetic material is used only for the IPM machine rotor where its special characteristics provide structural advantages. Silicon steel (M19) is retained for the stator in order to take advantage of its higher saturation flux density characteristics. It has been shown in [9] that the preferred design approach heat treats only the center posts to be nonmagnetic (i.e., $\mu_{r}=1$ ). Thin saturable bridges are retained at the ends of the cavities to attenuate the torque ripple.

The lumped-parameter magnetic circuit models for calculating $L_{q} / L_{d}$ and the magnet flux linkage have been modified appropriately to include the new regions of nonmagnetic material. Only a brief overview of the lumped-parameter models using conventional steel and the modifications needed for the introduction of the new bi-state magnetic material will be presented here. More details about the models and modifications are available in [9] and [11].

To introduce the lumped-parameter machine model, Fig. 2 shows the magnetic equivalent circuit for calculating the magnet flux linkage $\lambda_{\mathrm{PM}}$. Note that the $d$ axis is defined to be aligned with the magnet flux as shown in Fig. 2. The key assumption for using this model is that the bridges are fully saturated so that they can be modeled as constant flux sources shorting fixed amount of the magnet flux. The center posts regions are assumed to be heat treated into the material's nonmagnetic state, so the incremental permeability of the bridges and posts is assumed to be the same as that of air $\left(\mu_{r}=1\right)$. As a result, the lumped-parameter model for the $d$-axis magnet flux is effectively identical for the conventional and bi-state lamination materials, except that no constant flux source is needed for the center posts with the bi-state material in the absence of magnetic saturation in those regions.

The magnetic equivalent circuits for the $d$ - and $q$-axes inductance calculations are also unchanged as a result of the introduction of the bi-state magnetic material [9]. As for the case of the magnet flux linkage circuit discussed above, the permeability of the center post and bridge regions is assumed to be that of air for the purpose of calculating these inductances.

In actuality, FEA shows that the bridges in the baseline all-M19 direct-drive IPM machine are not fully saturated under light-load conditions [14]. This creates some error between the value of $L_{d}$ predicted by the lumped-parameter model and the actual measured value when the $d$-axis current is close to zero. This same observation applies to the new designs using the new bi-state magnetic material while retaining the saturated bridges, leading to some error in the light-load $L_{d}$ prediction that will be discussed in the next section of this paper.

\section{MACHINE DESIGN OptimiZATION RESUlts}

After implementing the necessary machine model modifications, the IPM machine design optimization software was exercised using the same performance specifications and test conditions that were used for the existing starter/alternator [11], [14]. The magnetic $B-H$ curve and loss characteristics 


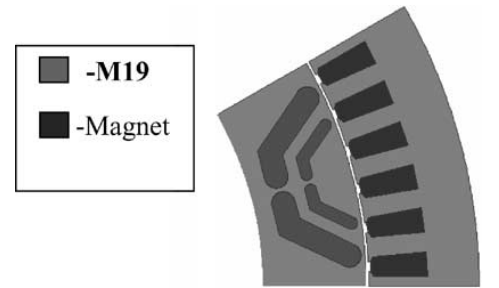

Fig. 3. Cross section of one pole of the baseline direct-drive S/A with M19 stator and rotor (1:1 speed ratio).

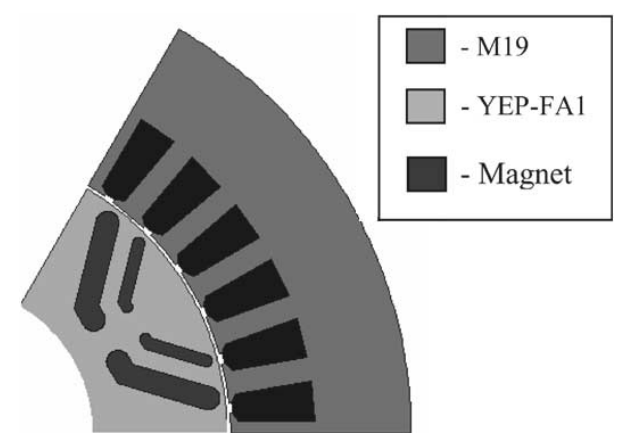

Fig. 4. Cross section of one pole of Design \#1 (3:1 speed ratio).

of the YEP-FA1 bi-state magnetic material were also added to the program, using data provided by the manufacturer [10].

As noted in Section II, the machine design software incorporates a lumped-parameter thermal model for the IPM machine [13]. The availability of this thermal model makes it possible to directly set maximum temperature limits for the magnets and stator windings rather than setting maximum stator current limits as an indirect surrogate for these thermal limits. Temperatures were checked for all of the key machine components for each candidate design for every test condition. Any candidate design that causes these thermal limits $\left(180^{\circ} \mathrm{C}\right.$ for stator windings and magnets) to be exceeded for any of the test conditions is eliminated from further consideration.

The machine design software was exercised leading to the identification of cost-optimized designs for four different speed ratios between $3: 1$ and $6: 1$. The maximum machine speed increases in direct proportion to the speed ratio while the machine torque requirement varies inversely. The estimated drive system cost of the machine combined with its inverter is used as the optimization criterion [11], consistent with the approach used to develop the optimum baseline design with M19 steel in both the stator and rotor.

\section{A. Optimized Machine Design Dimensions and Parameters}

Table II provides a summary of the key dimensions and design parameters for the optimized IPM machines developed for the four speed ratios using the new bi-state magnetic material. A tabulation of the corresponding data for the baseline starter/alternator machine using all M19 steel is included in the table for convenient comparisons. A cross-sectional view of one pole of the baseline direct-drive IPM machine using all M19 material is provided in Fig. 3 for reference. Figs. 4-7 provide pole cross sections for each of the new IPM machines using the bi-state magnetic material with increasing speed ratios.

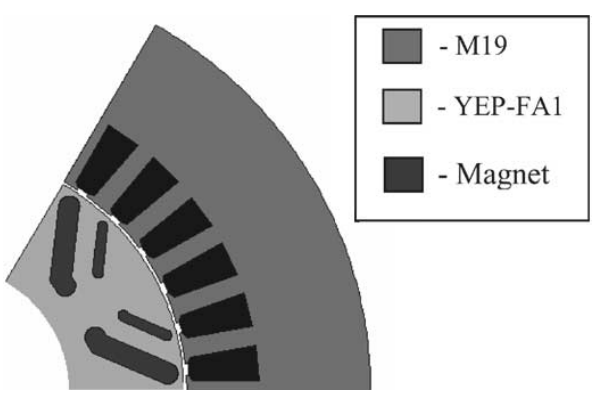

Fig. 5. Cross section of one pole of Design \#2 (4:1 speed ratio).

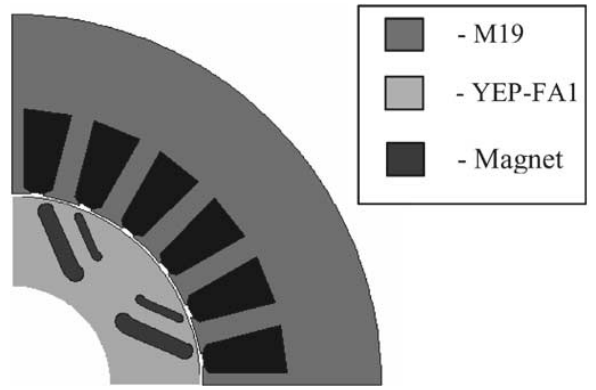

Fig. 6. Cross section of one pole of Design \#3 (5:1 speed ratio).

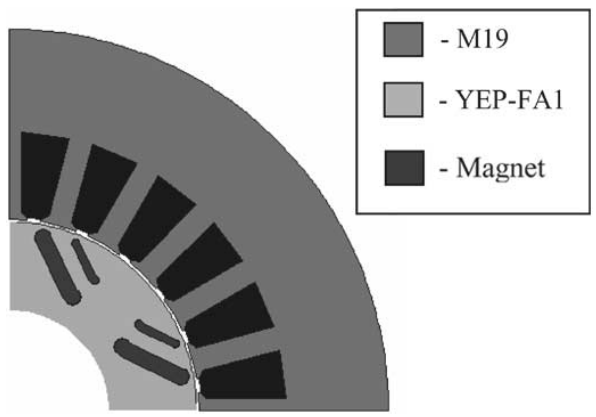

Fig. 7. Cross section of one pole of Design \#4 (6:1 speed ratio).

A key observation drawn from Table II and the accompanying figures is the significant increase in the center post thickness as the speed increases. Such wide center posts are unachievable using regular silicon steel because the magnet flux shunted by the posts would be excessive. Raising the speed ratio also causes the machine pole number, volume, and weight to decrease, consistent with expectations for high-speed PM synchronous machines.

\section{B. Electromagnetic FEA Results}

Electromagnetic FEA has been carried out to confirm the machine parameters calculated using the lumped-parameters models and to calculate the torque ripple for each of the four designs. The FEA software used for this analysis is MagNet2D by Infolytica.

As an example of the results of this work, FEA predicted that the fundamental-frequency (rms) component of the magnet flux linkage $\lambda_{\mathrm{PM} 1 \mathrm{rms}}$ for Design \#2 is $3.324 \mathrm{mWb}$.turns (rms). This value can be compared to $3.318 \mathrm{mWb}$ turns (rms) calculated for $\lambda_{\mathrm{PM} 1 \mathrm{rms}}$ using the lumped-parameter model, indicating very good agreement with only $0.17 \%$ difference between the two 
TABLE III

Comparison of Performance Metrics for the Baseline Direct-Drive S/A Machine and the Four Offset-Coupled DesignS

\begin{tabular}{|c|c|c|c|c|c|}
\hline & $\begin{array}{l}\text { Baseline Direct- } \\
\text { Drive S/A (M19 } \\
\text { Stator \& Rotor) } \\
\text { 1:1 Speed Ratio }\end{array}$ & $\begin{array}{c}\text { Design \#1: } \\
\text { Non-Magnetic } \\
\text { Center Posts } \\
\text { 3:1 Speed Ratio }\end{array}$ & $\begin{array}{c}\text { Design \#2: } \\
\text { Non-Magnetic } \\
\text { Center Posts } \\
\text { 4:1 Speed Ratio }\end{array}$ & $\begin{array}{c}\text { Design \#3: } \\
\text { Non-Magnetic } \\
\text { Center Posts } \\
\text { 5:1 Speed Ratio }\end{array}$ & $\begin{array}{c}\text { Design \#4: } \\
\text { Non-Magnetic } \\
\text { Center Posts } \\
\text { 6:1 Speed Ratio }\end{array}$ \\
\hline Base Voltage & 19.3 [Vrms] & $19.3[\mathrm{Vrms}]$ & $19.3[\mathrm{Vrms}]$ & $19.3[$ Vrms] & $19.3[\mathrm{Vrms}]$ \\
\hline $\begin{array}{c}\text { Stator Current [@150 } \\
\text { N-m] }\end{array}$ & 327 [Arms] & 390 [Arms] & 400 [Arms] & 470 [Arms] & 430 [Arms] \\
\hline $\begin{array}{l}\text { Maximum rms switch } \\
\text { current }\end{array}$ & 231 [Arms] & 276 [Arms] & 283 [Arms] & 332 [Arms] & 304 [Arms] \\
\hline PM flux linkage & $6.3[\mathrm{mWb}]$ & $3.68[\mathrm{mWb}]$ & $3.32[\mathrm{mWb}]$ & $4[\mathrm{mWb}]$ & $3.3[\mathrm{mWb}]$ \\
\hline Maximum back emf & $23.9[\mathrm{Vrms}]$ & $20.81[\mathrm{Vrms}]$ & $25.02[\mathrm{Vrms}]$ & 25.18 [Vrms] & $24.86[\mathrm{Vrms}]$ \\
\hline Phase Resistance & $10.3[\mathrm{~m} \Omega]$ & $4.4[\mathrm{~m} \Omega]$ & $4.6[\mathrm{~m} \Omega]$ & $2[\mathrm{~m} \Omega]$ & $2[\mathrm{~m} \Omega]$ \\
\hline Air gap Shear Stress & $33.8[\mathrm{kPa}]$ & $37.1[\mathrm{kPa}]$ & $40.2[\mathrm{kPa}]$ & $35.8[\mathrm{kPa}]$ & $32.3[\mathrm{kPa}]$ \\
\hline $\begin{array}{l}\text { Pk-Pk Torque Ripple } \\
\text { for Teavg }=150 \mathrm{~N}-\mathrm{m}\end{array}$ & $<10 \%$ & $\sim 28 \%$ & $\sim 46 \%$ & $\sim 43 \%$ & $\sim 46 \%$ \\
\hline Mass of copper & $1.92[\mathrm{~kg}]$ & $1.52[\mathrm{~kg}]$ & $1.11[\mathrm{~kg}]$ & $1.87[\mathrm{~kg}]$ & $1.76[\mathrm{~kg}]$ \\
\hline Mass of M19 & $11.55[\mathrm{~kg}]$ & $6.69[\mathrm{~kg}]$ & $5.98[\mathrm{~kg}]$ & $6.76[\mathrm{~kg}]$ & $6.85[\mathrm{~kg}]$ \\
\hline Mass of YEP-FA1 & $0[\mathrm{~kg}]$ & $2.75[\mathrm{~kg}]$ & $1.88[\mathrm{~kg}]$ & $1.82[\mathrm{~kg}]$ & $1.7[\mathrm{~kg}]$ \\
\hline Mass of magnets & $2.25[\mathrm{~kg}]$ & $0.91[\mathrm{~kg}]$ & $0.64[\mathrm{~kg}]$ & $0.46[\mathrm{~kg}]$ & $0.37[\mathrm{~kg}]$ \\
\hline $\begin{array}{c}\text { Electromagnetic } \\
\text { Weight }\end{array}$ & $15.6[\mathrm{~kg}]$ & $11.87[\mathrm{~kg}]$ & $9.61[\mathrm{~kg}]$ & $10.91[\mathrm{~kg}]$ & $10.7[\mathrm{~kg}]$ \\
\hline Saliency Ratio $(L q / L d)$ & 4.88 & 5.48 & 5.61 & 5.64 & 5.73 \\
\hline Estimated Copper Cost & \$US 9.6 & \$US 7.6 & \$US 5.6 & \$US 9.4 & \$US 8.8 \\
\hline Estimated M19 Cost & \$US 13.8 & \$US 6.69 & \$US 5.98 & \$US 7.76 & \$US 6.85 \\
\hline $\begin{array}{c}\text { Estimated YEP-FA1 } \\
\text { Cost }\end{array}$ & SUS 0 & SUS 11 & \$US 7.56 & \$US 6.84 & \$US 6.23 \\
\hline Estimated Magnet Cost & \$US 24.8 & \$US 10.1 & \$US 7 & \$US 5 & \$US 4.1 \\
\hline $\begin{array}{c}\text { Estimated Machine } \\
\text { Cost }\end{array}$ & \$US 69 & \$US 58 & \$US 43 & \$US 50 & \$US 47 \\
\hline $\begin{array}{l}\text { Estimated Converter } \\
\text { Cost }\end{array}$ & \$US 535 & \$US 556 & \$US 559 & \$US 582 & SUS 569 \\
\hline Estimated System Cost & SUS 604 & \$US 614 & \$US 602 & SUS 632 & SUS 616 \\
\hline
\end{tabular}

results. The magnet flux linkage results for the three other designs also showed very good agreement between FEA and the lumped-parameter model.

Similar to results achieved in previous work [11], the electromagnetic FEA calculated $L_{q}$ versus $I_{q}$ and $L_{d}$ versus $I_{d}$ relationships that exhibited very good agreement with the lumped-parameter model results. The only significant discrepancy was in the $L_{d}$ versus $I_{d}$ curves at low values of $I_{d}$, caused by the incomplete saturation of the bridges as discussed earlier in Section II.

Taken together, these FEA results sustain confidence in the validity of the predictions of the lumped-parameter model that includes the modifications in the rotor magnetic circuits required by the introduction of the nonmagnetic material in the center post regions.

\section{Optimized Machine Metrics and Performance Comparisons}

Table III provides a summary of several key metrics and performance characteristics for the four new machine designs using the bi-state magnetic material as well as for the baseline all-M19 direct-drive machine. It should be noted that all of the new machine designs have a relatively high value of saliency ratio $\left(L_{q} / L_{d}\right)$ between 5-6. This feature makes it possible to achieve a wide constant-power speed range without suffering from excessive back electromotive force (EMF) at the top end of the speed range [11]. An accompanying pair of bar charts in Figs. 8 and 9 provides convenient visual comparisons of two of the

\section{Electromagnetic Weight}

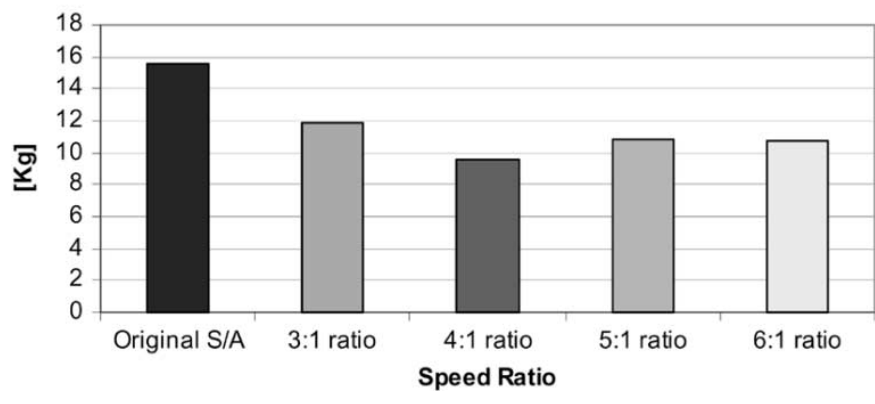

Fig. 8. Calculated electromagnetic weight comparisons for the five designs.

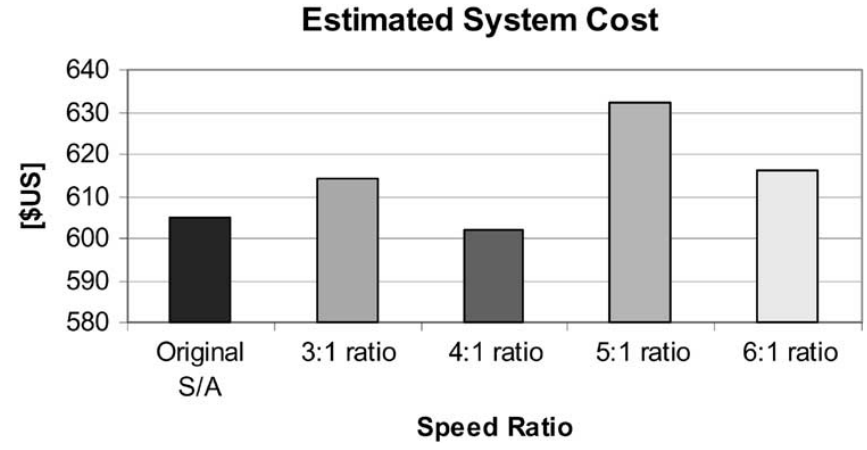

Fig. 9. Estimated machine-plus-converter system cost comparison for the five machine designs. Note the suppressed zero in the cost axis. 
key metrics including electromagnetic weight and drive system (motor plus converter) cost, respectively.

Inspection of the results in Table III and Figs. 8 and 9 reveals that Design \#2 (4:1 speed ratio) yields the best results among the five machines in terms of maximum machine power density and minimum estimated machine and drive system cost. The stator current amplitudes in the new designs are all higher than for the baseline machine because the lower magnetic saturation level of the bi-state magnetic material must be compensated by higher electric loading, leading to higher currents.

Fig. 8 shows a comparison of the electromagnetic weights among the five machines. Design \#2 demonstrates the lowest weight, achieving nearly a $40 \%$ improvement compared to the baseline direct-drive S/A. The estimated machine cost of the five machines follows almost identical trends, with Design \#2 again the lowest by nearly $40 \%$ compared to the direct-drive $\mathrm{S} / \mathrm{A}$. The higher cost per kilogram of the bi-state magnetic material is more than offset in all of the four new designs by the smaller amount of rotor material required compared to the baseline machine.

Fig. 9 compares the estimated motor-plus-converter drive system cost (note the suppressed zero) for the five machine designs. No costs for belts or gears are included for the offset-coupled designs. The estimated cost of the Design \#2 drive is lower than for all of the other three offset-coupled designs and, in fact, is marginally lower than that of the baseline S/A machine drive. This is significant improvement compared to an earlier design of a direct-drive S/A machine using the bi-state material [9] that resulted in a net drive system cost increase by $6 \%$ compared to the baseline all-M19 machine.

The cost estimates in Table III and Fig. 9 do not include any special provisions to account for the cost of heat treating the bridge or center post regions of the rotor laminations. Since the purpose of this research has been to establish the technical feasibility of this approach, the incremental cost of the heat treatment on a production basis lies beyond the scope of this paper. Establishing the commercial practicality of such designs raises important issues that will require separate investigations by researchers specializing in the manufacturing technologies appropriate for this type of machine construction. However, the expanding applications of industrial lasers in a wide variety of manufacturing processes raises hopes that the incremental costs of performing the lamination heat treatment can be reduced to modest levels.

The same FEA approach was used to calculate the torque ripple of the new machine designs over one slot pitch. The stator current is adjusted to the value required to deliver $150 \mathrm{~N} \cdot \mathrm{m}$ to the main engine crankshaft in each case. The results tabulated in Table III represent worst case results, since neither the stator nor rotor is skewed or provided with any special means for minimizing the torque ripple.

The FEA results for the four machines show that the torque ripple generally increases with the speed ratio. The main reason for this increase is that the widths of the rotor magnet center posts increase significantly to improve the rotor structural integrity as the speed increases. The nonmagnetic center posts distort the magnet flux waveform in the machine's air gap, contributing to the noted increase in torque ripple.
The detailed FEA results serve as a credible source of confirmation for the electromagnetic performance predicted by the lumped-parameter model. The confidence in the results is strengthened by the fact that the accuracy of the lumped-parameter model of the IPM machine has been experimentally verified using a different IPM machine with M19 steel laminations in the stator and rotor [11], [12]. This IPM machine shares the same basic two-barrier rotor configuration adopted for the machine designs in this paper.

\section{Structural FEA}

Structural FEA has been performed on all four designs using the commercial package ANSYS in order to confirm the structural integrity of the rotors. Two of the key rotors speeds considered during this analysis included: 1) the maximum generating speed $n_{\mathrm{mg}}$ that equals the maximum engine speed $(6000 \mathrm{r} / \mathrm{min})$ multiplied by the machine's speed ratio and 2) the maximum overspeed $n_{\mathrm{OS}}$ corresponding to $10000 \mathrm{r} / \mathrm{min}$ multiplied by this same speed ratio.

In addition, the yield threshold rotor speed $n_{\mathrm{yt}}$ is also determined, defined as the speed at which the yield stress in the bi-state material is first reached locally anywhere in the rotor lamination. This yield threshold speed provides a very conservative indicator of the machine's safe operating speed range since only localized plastic yielding of the material will be initiated at this speed without threatening the overall integrity of the rotor structure.

The nature of the contact surfaces between the rotor magnets and the walls of rotor lamination cavities has a significant impact on the peak stresses in the bi-state material. Peak stresses at the three speeds defined above were calculated using a conservative assumption of nonlinear contact between the two surfaces, allowing for relative motion of the materials (i.e., slip). Under these conditions, the magnet motion in the cavities at high speeds results in stress concentrations, causing higher peak stresses to be exerted on the rotor laminations.

A more favorable assumption regarding this interface is that the magnet material is sufficiently pliant that it stretches with the bi-state lamination material at high speeds so that there is no relative motion along any of the cavity perimeters (i.e., no slip). The peak mechanical stress in the bi-state material is calculated at the maximum overspeed $\left(n_{\mathrm{OS}}\right)$ condition using both assumptions to provide an interesting comparison between the nonlinear contact and no-slip conditions. The resulting peak stress is significantly lower under the no-slip assumption since the magnet centrifugal force is spread more uniformly along the magnet-lamination interfaces. The "correct" assumption likely lies somewhere between these extremes depending on the composition and mechanical characteristics of the chosen magnet material (i.e., sintered versus bonded).

As typical examples of these structural FEA results, the predicted Von Mises stress distributions for Design \#2 (4:1) at $40000 \mathrm{r} / \mathrm{min}$ overspeed conditions $\left(n_{\mathrm{OS}}\right)$ under assumptions of slip and no-slip contact surfaces are shown in Figs. 10 and 11, respectively. The Von Mises stress is selected as the preferred stress metric for all of the results presented in this section since it reflects the combined mechanical stress in the radial and angular dimensions. It should be noted that the peak stress point 


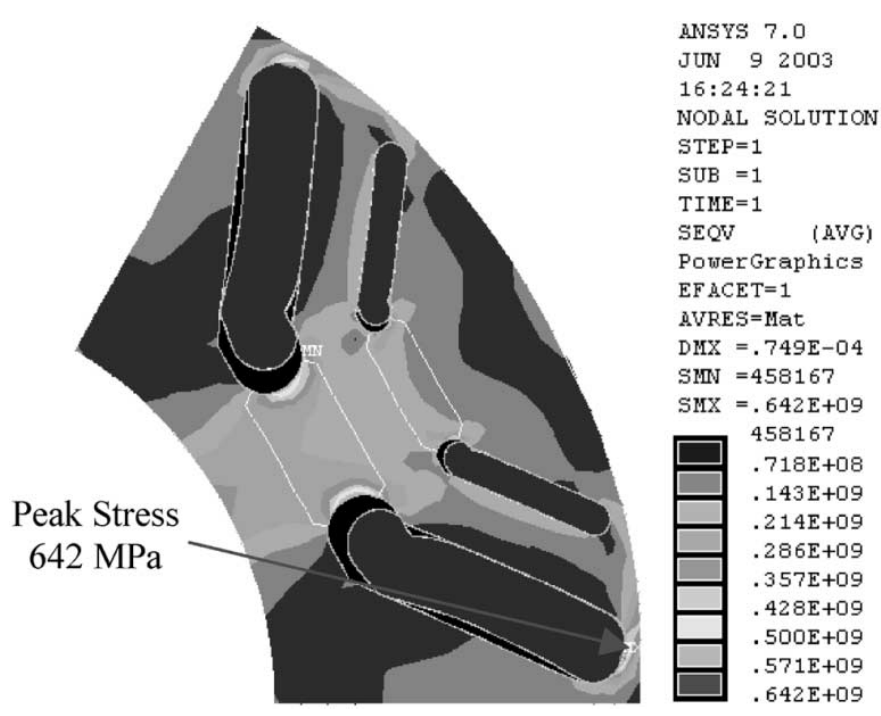

Fig. 10. Von Mises stress distribution at $40000 \mathrm{r} / \mathrm{min}$ assuming nonlinear contact (slip) between the magnets and laminations for Design \#2 (4:1 speed ratio).
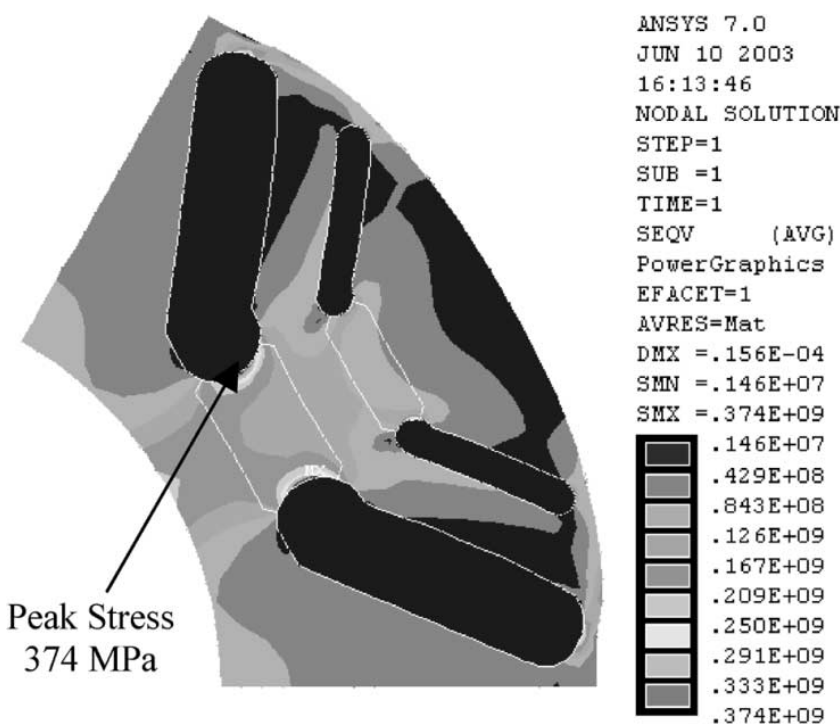

Fig. 11. Von Mises stress distribution at $40000 \mathrm{r} / \mathrm{min}$ (overspeed) assuming no slip between the magnets and laminations for Design \#2 (4:1 speed ratio).

migrates from the bridge to the center post when the assumption of nonlinear contact (Fig. 10) is changed to no slip (Fig. 11), and the peak stress value drops significantly.

Key results for all four designs under the four test conditions defined above are summarized in Table IV. Each individual entry in this table includes the machine's rotational speed ( $\mathrm{r} / \mathrm{min})$, the corresponding rotor tip speed $(\mathrm{m} / \mathrm{s})$, and the peak Von Mises stress found in the center post and bridge, respectively (MPa). It is important to recall that the yield stress for the nonmagnetic center posts $(350 \mathrm{MPa})$ is lower than the yield stress for the magnetic bridges ( $640 \mathrm{MPa})$ based on the bi-state material properties listed earlier in Table I. Stress value entries in Table IV that exceed their corresponding yield stress values are italicized.

Major observations that can be drawn from the results in Table IV and the stress plots include the following.

Maximum Tip Speed: Entries in Table IV show that the maximum speed at the outer rotor surface increases monotonically
TABLE IV

Structural FEA Results For the Four Machine Designs

\begin{tabular}{c|c|c|c|c}
\hline & $\begin{array}{c}\text { Max Gen. } \\
\text { Speed (slip) } \\
n_{m g}\end{array}$ & $\begin{array}{c}\text { Yield } \\
\text { Threshold } \\
\text { Speed (slip) } \\
n_{y t}\end{array}$ & $\begin{array}{c}\text { Max } \\
\text { Overspeed } \\
\text { (slip) } n_{O s}\end{array}$ & $\begin{array}{c}\text { Max } \\
\text { Overspeed } \\
\text { (no slip) } n_{o s}\end{array}$ \\
\hline Des. & $18000[\mathrm{r} / \mathrm{min}]$ & $24000[\mathrm{r} / \mathrm{min}]$ & $30000[\mathrm{r} / \mathrm{min}]$ & $30000[\mathrm{r} / \mathrm{min}]$ \\
$\# 1$ & $102.73[\mathrm{~m} / \mathrm{s}]$ & $136.97[\mathrm{~m} / \mathrm{s}]$ & $171.22[\mathrm{~m} / \mathrm{s}]$ & $171.22[\mathrm{~m} / \mathrm{s}]$ \\
$(3: 1)$ & $193[\mathrm{MPa}](\mathrm{P})$ & $342[\mathrm{MPa}](\mathrm{P})$ & $535[\mathrm{MPa}](\mathrm{P})$ & $321[\mathrm{MPa}](\mathrm{P})$ \\
& $\sim 171[\mathrm{MPa}](\mathrm{B})$ & $\sim 304[\mathrm{MPa}](\mathrm{B})$ & $\sim 475[\mathrm{MPa}](\mathrm{B})$ & $\sim 250[\mathrm{MPa}](\mathrm{B})$ \\
\hline Des. & $24000[\mathrm{r} / \mathrm{min}]$ & $32000[\mathrm{r} / \mathrm{min}]$ & $40000[\mathrm{r} / \mathrm{min}]$ & $40000[\mathrm{r} / \mathrm{min}]$ \\
$\# 2$ & $122.90[\mathrm{~m} / \mathrm{s}]$ & $163.87[\mathrm{~m} / \mathrm{s}]$ & $204.83[\mathrm{~m} / \mathrm{s}]$ & $204.83[\mathrm{~m} / \mathrm{s}]$ \\
$(4: 1)$ & $\sim 205[\mathrm{MPa}](\mathrm{P})$ & $\sim 345[\mathrm{MPa}](\mathrm{P})$ & $\sim 535[\mathrm{MPa}](P)$ & $374[\mathrm{MPa}](P)$ \\
& $231[\mathrm{MPa}](\mathrm{B})$ & $388[\mathrm{MPa}](\mathrm{B})$ & $642[\mathrm{MPa}](\mathrm{B})$ & $\sim 291[\mathrm{MPa}](\mathrm{B})$ \\
\hline Des. & $30000[\mathrm{r} / \mathrm{min}]$ & $35000[\mathrm{r} / \mathrm{min}]$ & $50000[\mathrm{r} / \mathrm{min}]$ & $50000[\mathrm{r} / \mathrm{min}]$ \\
$\# 3$ & $137.60[\mathrm{~m} / \mathrm{s}]$ & $160.54[\mathrm{~m} / \mathrm{s}]$ & $229.34[\mathrm{~m} / \mathrm{s}]$ & $229.34[\mathrm{~m} / \mathrm{s}]$ \\
$(5: 1)$ & $\sim 330[\mathrm{MPa}](\mathrm{P})$ & $\sim 350[\mathrm{MPa}](\mathrm{P})$ & $\sim 720[\mathrm{MPa}](P)$ & $483[\mathrm{MPa}](P)$ \\
& $465[\mathrm{MPa}](\mathrm{B})$ & $633[\mathrm{MPa}](\mathrm{B})$ & $1300[\mathrm{MPa}](\mathrm{B})$ & $\sim 291[\mathrm{MPa}](\mathrm{B})$ \\
\hline Des. & $36000[\mathrm{r} / \mathrm{min}]$ & $41000[\mathrm{r} / \mathrm{min}]$ & $60000[\mathrm{r} / \mathrm{min}]$ & $60000[\mathrm{r} / \mathrm{min}]$ \\
$\# 4$ & $157.96[\mathrm{~m} / \mathrm{s}]$ & $179.90[\mathrm{~m} / \mathrm{s}]$ & $263.27[\mathrm{~m} / \mathrm{s}]$ & $263.27[\mathrm{~m} / \mathrm{s}]$ \\
$(6: 1)$ & $\sim 300[\mathrm{MPa}](\mathrm{P})$ & $\sim 350[\mathrm{MPa}](\mathrm{P})$ & $\sim 756[\mathrm{MPa}](\mathrm{P})$ & $\sim 485[\mathrm{MPa}](\mathrm{P})$ \\
& $490[\mathrm{MPa}](\mathrm{B})$ & $636[\mathrm{MPa}](\mathrm{B})$ & $1360[\mathrm{MPa}](\mathrm{B})$ & $545[\mathrm{MPa}](\mathrm{B})$ \\
\hline
\end{tabular}

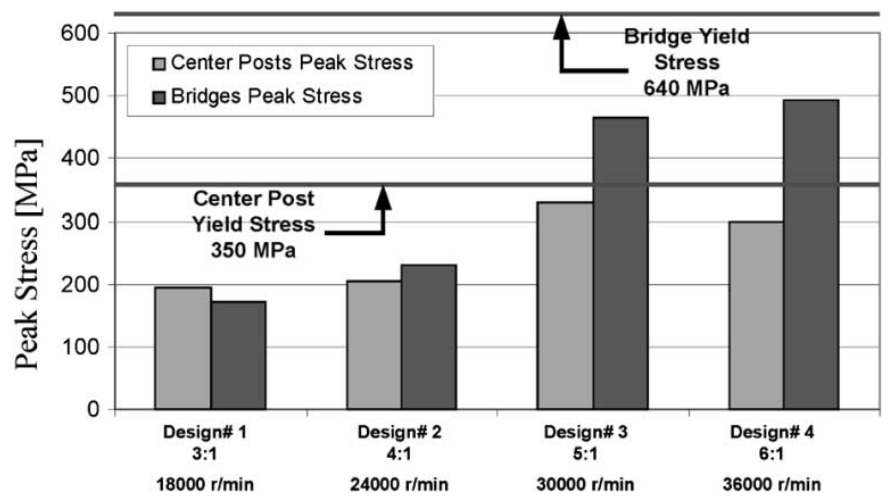

Fig. 12. Peak Von Mises stress at max generating speed assuming nonlinear contact (slip) between the magnets and laminations for the four designs.

from Design \#1 (3:1) to Design \#4 (6:1) for each of the test conditions. This is an indicator that the peak mechanical stress exhibited for each of the test conditions can be expected to generally increase as the speed ratio increases, and the FEA results bear out this hypothesis.

Maximum Generating Speed Operation: The peak Von Mises stress does not exceed the yield stress of the bi-state material anywhere in the rotor lamination at the maximum generating speed $n_{\mathrm{mg}}$ for any of the four designs under the more conservative assumption of nonlinear contact (slip). Fig. 12 provides a bar chart that plots these peak stress values in both the center posts and the bridges. The higher peak values approaching $500 \mathrm{MPa}$ in Designs \#3 $(5: 1)$ and \#4 $(6: 1)$ occur in the bridges where they fall safely within the associated yield stress of $640 \mathrm{MPa}$.

Yield Threshold Speed Operation: The calculated value of the yield threshold speed $n_{\mathrm{yt}}$ falls above the maximum generating speed $n_{\text {mg }}$ but below the maximum overspeed limit $n_{\mathrm{os}}$ for all four designs (nonlinear slip contact assumed). Fig. 13 provides a visual presentation of the yield threshold speed data, 


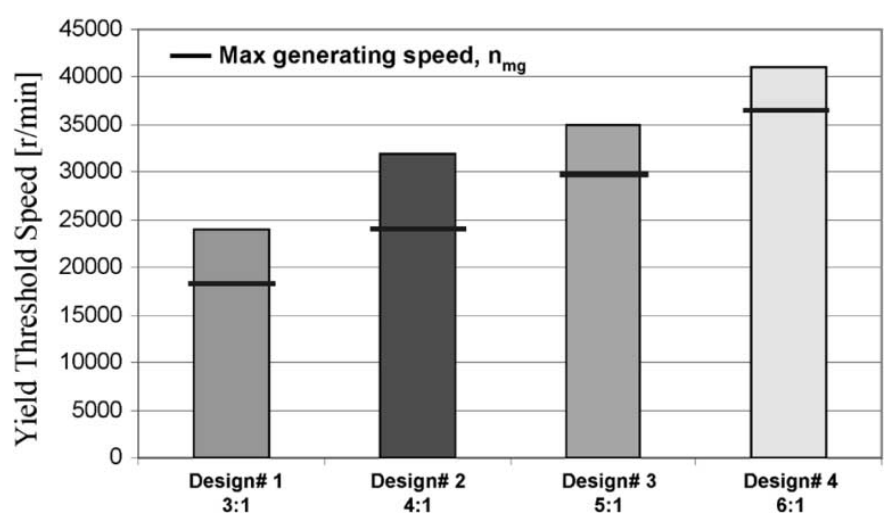

Fig. 13. Calculated yield threshold speed assuming nonlinear contact (slip) between the magnets and laminations for the four designs.

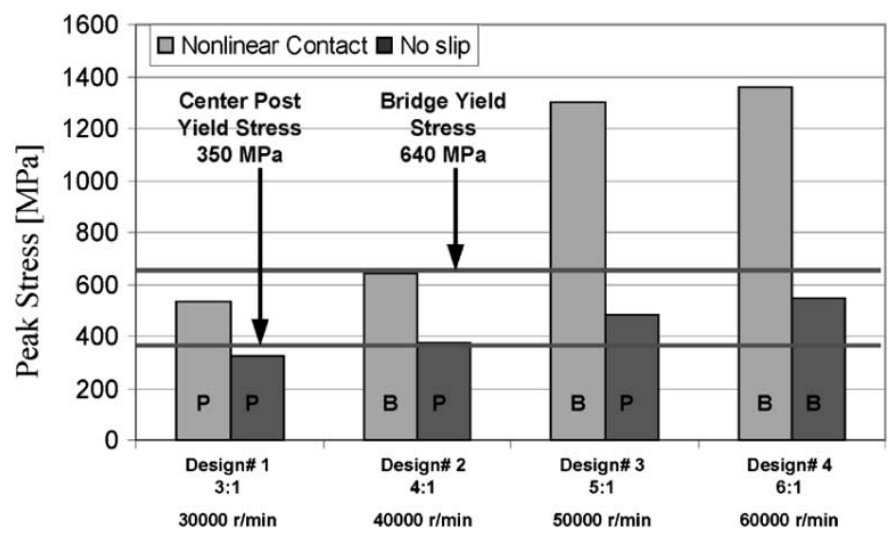

Fig. 14. Peak Von Mises stress at max overspeed for both cases of nonlinear contact and no slip between the magnets and laminations for the four designs.

including identification of the maximum generating speed $n_{\mathrm{mg}}$ for each machine. As described above, the $n_{\mathrm{yt}}$ value is a conservative indicator of the speed at which localized plastic yield begins at some specific point in either a bridge or post.

Maximum Overspeed Operation (Slip): The predicted peak stress locally exceeds the rotor lamination yield stress for all four designs at maximum overspeed $n_{\mathrm{os}}$ under the nonlinear contact (slip) assumption. The bar chart in Fig. 14 plots these peak stresses and uses the notation $P$ for center post and $B$ for bridge to identify where they occur. Inspection of Fig. 10 indicates that the regions in the bridges and posts where the yield stess is exceeded are quite highly localized in Design \#2 (4:1), and the same is true for Design \#1 $(3: 1)$. As a result, the overall rotor structural integrity of these two designs is expected to be sound at maximum overspeed, even in the presence of plastic yield in these specific regions.

On the other hand, the peak stresses predicted for Designs \#3 (5:1) and \#4 (6:1) for maximum overspeed conditions are considerably higher than for the other two designs. Closer inspection reveals larger areas of excessive stress, suggesting that these two designs are probably unsound for maximum overspeed operation, at least for conditions of nonlinear magnet-lamination contact (slip).

Maximum Overspeed Operation (No Slip): In contrast, the predicted peak stresses in the rotor lamination are considerably lower for maximum overspeed $n_{\mathrm{os}}$ for all four designs when no-slip conditions are assumed for the magnet interfaces. As indicated by entries in Table IV as well as in Fig. 14, the peak stress generally appears in the center posts for no-slip conditions. These stress values are highest for Designs \#3 (5:1) and \#4 (6:1), but tend to be highly localized so that the overall rotor structural integrity for all four designs is expected to remain sound under these no-slip overspeed conditions.

Taken together, these results suggest that Designs \#1 $(3: 1)$ and \#2 (4:1) will be able to maintain their structural integrity for all of the test conditions including maximum overspeed. In contrast, the structural integrities of Designs \#3 (5:1) and \#4 $(6: 1)$ are unlikely to be satisfactory unless the maximum overspeed $n_{\mathrm{os}}$ can be reduced.

\section{CONCLUSION}

This paper has demonstrated that the new bi-state soft magnetic material can be used to fullest advantage in the design of IPM machines when the rotor speed is permitted to increase. For the automotive S/A application studied here, machine designs with maximum speeds up to $40000 \mathrm{r} / \mathrm{min}$ have been successfully developed with promising results. Such speeds were not attainable using silicon steel rotor laminations because widened center posts effectively shorted the rotor magnets.

In addition to the advantage of increased power density provided by the elevated rotor speed, the size reduction offsets the expected cost premium of the bi-state material. Results to date indicate that the benefits of the bi-state material peak in the offset-coupled S/A application with a speed ratio of $4: 1$. This study opens the door to the investigation of other high-speed machine applications where the use of this new bi-state magnetic material would be advantageous.

\section{ACKNOWLEDGMENT}

The authors wish to thank S. Yokoyama and M. Mita of Hitachi Metals, Ltd., J. Kaneda of Hitachi Research Labs, and Dr. E. C. Lovelace of SatCon Technology Corporation for their generous assistance in carrying out this study. The authors gratefully acknowledge use of the facilities of the Wisconsin Electric Machines and Power Electronics Consortium (WEMPEC) during this investigation.

\section{REFERENCES}

[1] I. Takahashi, T. Koganezawa, G. Su, and K. Ohyama, "A super high speed PM motor drive system by a quasicurrent source inverter," Trans. Ind. Applicat., vol. 30, pp. 683-690, May/June 1994.

[2] A. Boglietti, M. Pastorelli, and F. Profumo, "High speed brushless motors for spindle drives," in Proc. Intl. Conf. Synchronous Machines (SM100), vol. 3, Zurich, Switzerland, 1991, pp. 817-822.

[3] A. Fratta, A. Vagati, and F. Villata, "Design criteria of an IPM machine suitable for field-weakened operation," in Proc. Int. Conf. Electric Machines, 1990, pp. 1059-1065.

[4] E. C. Lovelace, T. M. Jahns, T. A. Keim, and J. H. Lang, "Mechanical design considerations for conventionally-laminated IPM synchronous machine rotors," in Proc. IEEE Int. Conf. Electric Machines and Drives (IEMDC'01), Cambridge, MA, June 2001, pp. 163-169.

[5] S. Yokoyama and T. Inui, "Magnetic properties of $\mathrm{Fe}-\mathrm{Cr}-\mathrm{C}$ and Fe-Cr-C-Ni alloys," Tetsu-To-Hagane, vol. 88, no. 4, pp. 54-60, 2002. in Japanese.

[6] M. Mita, "Motor rotor with dual stage magnetic properties," in Proc. 13th Annu. Symp. Incremental Motion Control Systems and Devices, Champaign, IL, July 2001, pp. 123-127. 
[7] M. Mita, N. Hirao, and F. Kimura, "A study of retainer ring made of $13.5 \mathrm{Cr}-0.6 \mathrm{C}-\mathrm{Fe}$ dual state magnetic material," J. Magn. Magn. Mater. 254-255, pp. 272-274, 2003.

[8] _ "Magnetic screw rod using dual state $0.6 \mathrm{C}-13 \mathrm{Cr}-\mathrm{Fe}$ bulk magnetic material," J. Appl. Phys., vol. 91-10, pp. 6997-6999, 2002.

[9] A. M. EL-Refaie and T. M. Jahns, "Application of Bi-state magnetic material to an automotive IPM starter/alternator machine," in Proc. 2003 IEEE Int. Electric Machines and Drives Conf. (IEMDC'03), Madison, WI, June 2003, pp. 1379-1387.

[10] "Properties of composite magnetic material YEP-FA1," Metallurgical Res. Lab, Hitachi Metals, Ltd., Shimane, Japan, Data Sheet 020113MG, Jan. 2002.

[11] E. C. Lovelace, "Optimization of a magnetically saturable interior PM synchronous machine drive," Ph.D. dissertation, Dept. Elect. Eng. Comput. Sci., Massachusetts Inst. Technol., Cambridge, MA, 2000

[12] E. C. Lovelace, T. M. Jahns, and J. H. Lang, "A saturating lumped-parameter model for an interior PM synchronous machine," IEEE Trans. Ind. Applicat., vol. 38, pp. 645-650, May/June 2002.

[13] A. M. EL-Refaie, N. C. Harris, T. M. Jahns, and K. M. Rahman, "Thermal analysis of multi-barrier IPM synchronous machine using lumped parameter model," in Proc. Int. Conf. Electric Machines (ICEM'02), Brugges, Belgium, Aug. 2002, CD-ROM.

[14] E. C. Lovelace et al., "Design and experimental verification of a directdrive interior PM synchronous machine using a saturable lumped-parameter model," in Conf. Rec. IEEE-IAS Annu. Meeting, Pittsburgh, PA, Oct. 2002, pp. 2486-2492.

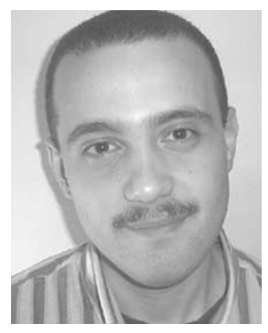

Ayman M. EL-Refaie (S'95) received the B.Sc and M.Sc. degrees in electrical power engineering in 1995 and 1998, respectively, from Cairo University, Cairo, Egypt, and the M.Sc. degree in electrical engineering in 2002 from the University of Wisconsin Madison, where he is currently working toward the $\mathrm{Ph} . \mathrm{D}$. degree in the Wisconsin Electric Machines and Power Electronics Consortium (WEMPEC)

Between 1995-1998 he was an Assistant Lecturer at Cairo University and the American University in Cairo. He participated in many projects involving the design of electrical power distribution systems. Since 1999, he has been a Research Assistant at the University of Wisconsin, Madison. His interests include electrical machines and drives.

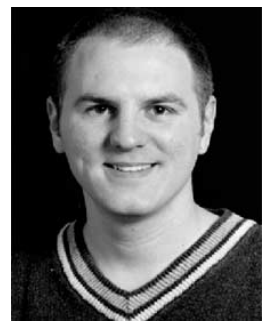

Russell Manzke received the B.S.M.E. degree from the University of Wisconsin, Madison.

His studies at the University of Wisconsin focused on three-dimensional modeling and analysis. In the spring of 2001, he studied mechanical modeling and analysis at ENSICA, an aviation engineering schoo in Toulouse, France. He is currently a Mechanical Engineer with the Wisconsin Center for Space Automation and Robotics, University of Wisconsin, Madison, WI, where he designs biological experiments for the International Space Station.

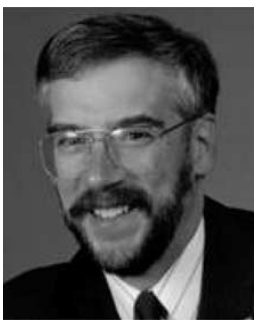

Thomas M. Jahns (S'73-M'79-SM'91-F'93) received the S.B. and S.M. degrees in 1974 and the $\mathrm{Ph} . \mathrm{D}$. degree in 1978 from Massachusetts Institute of Technology, Cambridge, all in electrical engineering.

He joined the faculty of the University of Wisconsin, Madison, in 1998 as a Professor in the Department of Electrical and Computer Engineering, where he is also an Associate Director of the Wisconsin Electric Machines and Power Electronics Consortium (WEMPEC). Prior to joining the University of Wisconsin, he was with GE Corporate Research and Development, Schenectady, NY, for 15 years, where he pursued new power electronics and motor drive technology in a variety of research and management positions. His research interests include permanent-magnet synchronous machines for a variety of applications ranging from high-performance machine tools to low-cost appliance drives. During 1996-1998, he conducted a research sabbatical at the Massachusetts Institute of Technology, where he directed research activities in the area of advanced automotive electrical systems and accessories as co-director of an industry-sponsored automotive consortium.

Dr. Jahns was awarded the William E. Newell Award by the IEEE Power Electronics Society (PELS) in 1999. He was recognized as a Distinguished Lecturer by the IEEE Industry Applications Society (IAS) during 1994-1995 and by PELS during 1998-1999. He served as President of PELS (1995-1996) and as a Member of the IAS Executive Board from 1992 to 2001. 